\title{
One Stage Anterior Reconstruction and Posterior Instrumentation in Surgical Management of Thoracolumbar Spine Fractures
}

\author{
Khaled Omran, Hesham Ali, Ahmed Saleh, Ahmed Omar, Ibrahim Elhawery, \\ Ali Zein A. A. Alkhooly* \\ Faculty of Medicine, El-Minia University, El-Minia, Egypt \\ Email: "profalizein@yahoo.com
}

Received 15 December 2014; accepted 23 January 2015; published 28 January 2015

Copyright (C) 2015 by authors and Scientific Research Publishing Inc.

This work is licensed under the Creative Commons Attribution International License (CC BY).

http://creativecommons.org/licenses/by/4.0/

(c) (i) Open Access

\begin{abstract}
Background: The different methods of anterior reconstruction and posterior instrumentation in surgical management of thoracolumbar spine fractures are PLIF, TLIF, lateral extracaviatary and transpedicular techniques which are increasingly used to perform partial or total corpectomies and anterior reconstructions from a posterior approach. These techniques were being alternative to the standard anterior approach with less morbidity and mortality. Patients and Methods: This study was performed between 2011 and 2014 on 100 patients with acute unstable thoracolumbar spine fractures which were divided into four groups: 30 patients underwent (TLIF), 28 patients underwent (PLIF), 28 patients underwent (PA) and 14 patients underwent (TPA). Neurological outcome, complications, operative times, kyphotic angle, vertebral height loss, spinal canal compromise, pulmonary functions, Denis pain and work scale, VAS score, ODI score, hospital stay, and estimated blood loss (EBL) were evaluated and compared in between the four groups. Results: There was a higher complication rate, increased EBL, and longer operative time with posteroanterior (PA) compared with PLIF, TLIF and (TPA). Patients undergoing PLIF, TLIF and TPA had a greater recovery of neurological function than those in whom PA were performed. Conclusion: TPA appeared to have more favorable results in improving the clinical and radiological outcome and no complications were reported apart from superficial wound infection which healed rapidly. The PLIF, TLIF and TPA appeared to have a comparable morbidity rate to PA. The different methods of anterior reconstruction from posterior approach are more favorable, applicable and convenient than PA approach.
\end{abstract}

\section{Keywords}

Transpedicular Approach (TPA), Postero-Anterior Approach (PA), Posterior Lumbar Interbody

\footnotetext{
${ }^{*}$ Corresponding author.
}

How to cite this paper: Omran, K., et al. (2015) One Stage Anterior Reconstruction and Posterior Instrumentation in Surgical Management of Thoracolumbar Spine Fractures. Open Journal of Orthopedics, 5, 6-15. 


\section{Introduction}

Spinal column injuries represent approximately 3\% of all trauma cases. Among the spine injuries $90 \%$ involve the thoracic and lumbar region [1]. The thoracolumbar junction is more susceptible to injury than other portions of the spine. Approximately 50 percent of all vertebral body fractures and 40 percent of all spinal cord injuries occur from T11 to L2 [2]. Thoracolumbar fractures occur as a result of different mechanisms of injuries on the spinal column which often causes displacement into the vertebral canal and reduces the diameter causing mechanical compression of the canal and neurological deficit [3]. Thoracolumbar fractures should be managed surgically to protect and improve the neurological function, stabilize the spine, early mobilization and rehabilitation, and minimize the pain and subsequent deformity [4]. There are three surgical approaches to direct decompression: the anterior approach, posterior approach and the combined approach [5] [6]. Both parts of surgery are to be done in a single stage or two stages, but when anterior and posterior surgery is performed in a single-stage it expedites rehabilitation and recovery [7]. The most effective treatment is vertebral canal decompression and stabilization of the vertebral column through an anterior approach [8], but the morbidity of this approach is higher than that of posterior pedicle screw approach [9]. The anterior column of the thoracolumbar junction, however, may be approached either by using deep lateral thoracotomy or thoracoscopy [10] or from a single posterior approach using a modified posterior lumbar interbody fusion/transforaminal lumbar interbody fusion (PLIF/TLIF) technique and transpedicular or posterolateral approach [11]. The higher morbidity and mortality rate reported with direct anterior surgery and higher implant failure with posterior fixation alone motivate us to search about other different methods of decompression with simultaneous anterior reconstruction and posterior fixation in thoracolumbar spine fractures. The different techniques used in this study used to be alternative to one stage or staged combined surgery. The purpose of this study is prospective evaluation and assessment of the clinical and radiological results of patients with acute traumatic thoracolumbar fractures treated with simultaneous posterior fixation and anterior reconstruction using four different methods of decompression such as lateral extracavitary (PA), PLIF, TLIF and TPA and comparing between the results of these different techniques.

\section{Patients and Methods}

This randomized prospective study is carried out from June 2011 to May 2014 on 100 patients with acute thoracolumbar spine fractures with neurological deficits were managed by four different surgical techniques. Inclusion criteria: single level, acute ( $<3$ weeks after injury), unstable spine fracture including T11, T12, L1 and L2 with neurological deficit, load sharing class $>6$ score, TLISS (thoracolumbar injury severity score) $>5$ score and white and Panjabi score $>6$ score. Exclusion criteria: patients with osteoporotic or pathological, multiple vertebral fractures, thoracolumbar fracture dislocation and pediatric spine injuries. 60 male patients and 40 female within an age range of 18 - 50 years. Levels of injury were L1 in 42 cases, L2 in 24 cases, T12 in 20 cases, and T11 in 14 cases. Mechanisms of injury were fall from height in 50 cases, motor cyclist accident in 22 cases and motor car accident in 28 cases. Fifty four patients had associated fractures (22 cases had fracture calacaneus, 16 cases had fracture ribs, 8 cases had fracture talus, 6 cases had fracture distal radius and 2 cases had fracture tibia). Preoperative neurological state according to ASIA motor index was A in 6 cases, B in 28 cases, C in 26 cases and D in 20 cases.

The fracture anatomy was evaluated routinely by X-ray and CT scan. MRI was performed for evaluation of the neural affection and ligamentous injuries. All patients were assessed according to Denis classification; load sharing, MacAfee's, Mageral's, TLISS classification and white Panjabi method. Vertebral height loss (VHL) ratio, kyphotic angle and spinal canal compromises were assessed pre/postoperatively and last final follow up.

Pain severity, neurological and functional outcomes were assessed preoperative and postoperatively by the Visual Analogue Score (VAS), American Spinal Injury Association (ASIA) motor index and Oswestery Disability Index (ODI) respectively. Denis pain and work scale were evaluated postoperatively in all patients. All the patients were evaluated neurological improvement, functional outcome, radiological outcome and complications. All the patients were followed up for 6 - 36 months. 
There were 30 patients (30\%) in group A TLIF (TTIF), 28 patients (28\%) in group B (PLIF), 28 patients (28\%) in group C (PA) and 14 patients (14\%) in group D (TPA).

\subsection{Surgical Technique}

Preoperatively, all patients were received intravenous prophylactic antibiotics. All the patients underwent surgery under general and hypotensive anesthesia and in prone position. The level of vertebrae involved was identified preoperatively by a skin marking under C-arm. A midline incision was made. The paraspinal muscles were subperiostealy dissected using Cobb's dissectors and retracted. The lamina was exposed and the facet was cleared off the soft tissues and any bleeding was secured by proper haemostasis using bipolar diathermy. The pedicle was identified and pedicle screw of adequate length and diameter was inserted one or two levels above, below the injured segment and in the fractured vertebra usually on the right side and the left side was left free to allow decompression and reconstruction of anterior column. The screw placement was rechecked by C-arm. The Titanium rod has been measured, cut and fixed on one side usually the right side to allow distraction in required situations.

In group (I) TLIF (TTIF) technique as shown in Figure 1: The posterior lamina of the injured vertebra was removed and decompression of the neural elements was approached by removing lamina of single or both side with complete facetectomy to allow the bony fracture fragment causing mechanical compression to be easily removed by using specially designed curettes or impacted by a specially designed L-impactor or removed adequately and allow neuroforminal decompression without fear of dural tear or excessive manipulation on the neural element. After decompression of the canal, the nearby disc was opened and currated and removed by multiple dilator and the currated disc was filled by bone graft alone or bone graft with central single TLIF fibrocarbon cage. After that release of distraction, slight axial compression was done by compressing the pedicular screws in the vertebrae above and below. The decompression was checked and confirmed. The Titanium rods were measured; cut, placed and slight compression applied.

In group (II) PLIF technique: the same steps were done as in (TLIF) group except: complete decompression was done by laminectomy without complete facatectomy. PLIF fibrocabon cage was used to fill the currated disc.

In group (III) PA technique as shown in Figure 2: after posterior fixation, the patient then was turned to the lateral decubitus position (left side is upwards); left transverse incision was based perpendicular on the posterior midline longitudinal incision or from extensile posterior midline incision. The intramuscular plane was between logismmus coli and illocostilis muscle. The 12th and 11th rib was exposed and removed extraperiostealy until its costoverteberal junctions. The transverse process in L1 and L2 was being ostomotized or origin of illopsoase muscle was being subperiostelly dissected from transverse process to enter the extracaviatary space to allow indirect decompression of the spinal canal. Nerve root and disc above and below was exposed and roots freely mobilized. After exposure of the lateral surface vertebra, a blunt spatula was put over the anterolateral surface of

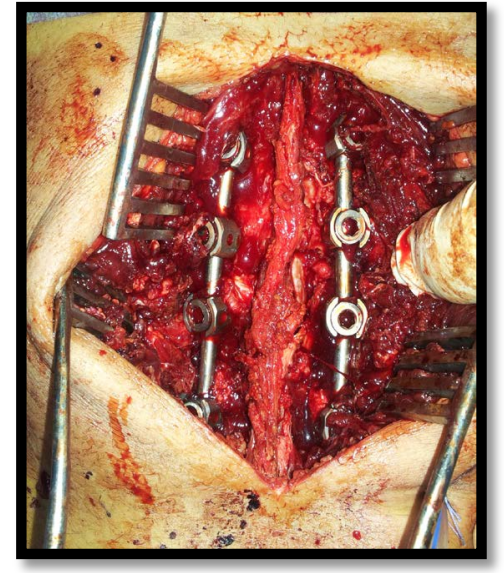

(a)

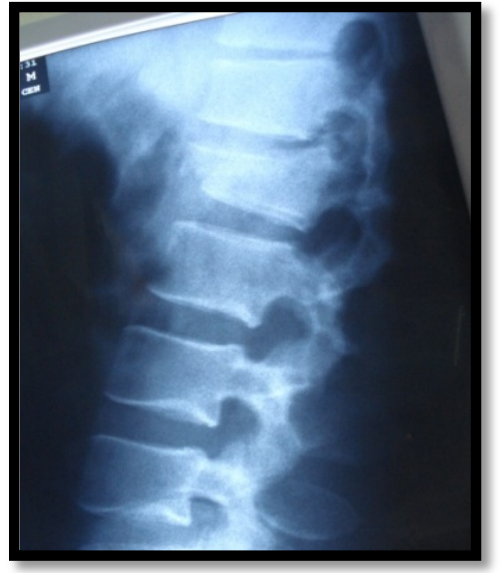

(b)

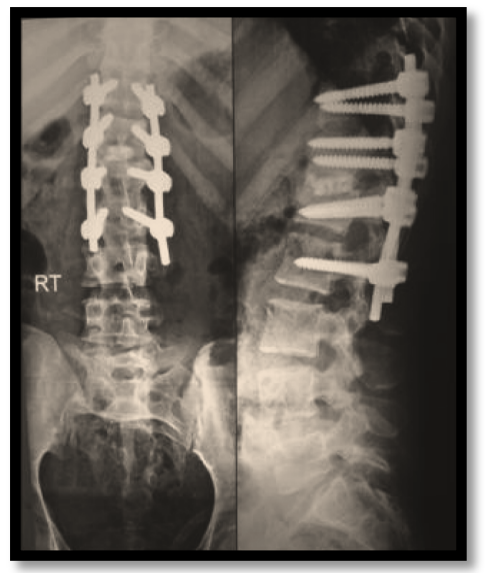

(c)

Figure 1. Showing TLIF technique and case of burst fracture L1 treated by TLIF cage and posterior fixation. 


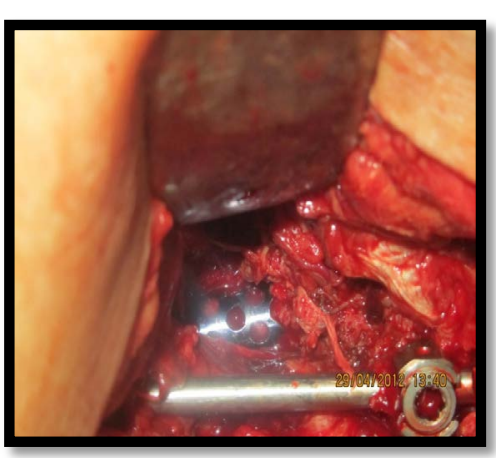

(a)

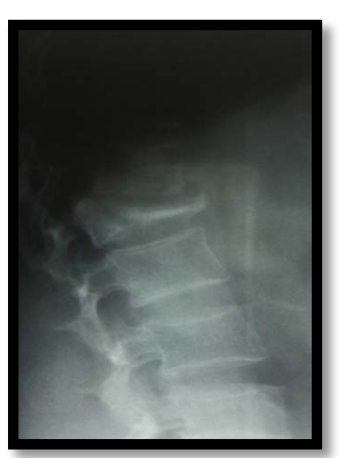

(b)

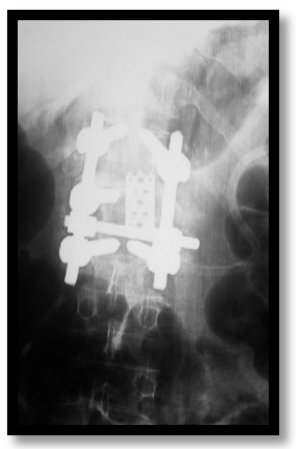

(c)

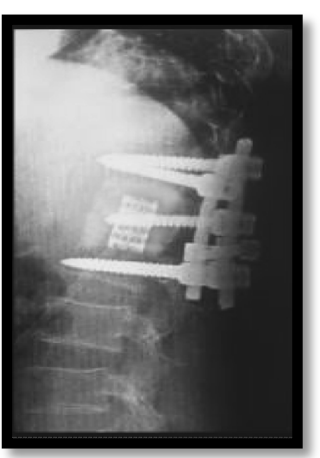

(d)

Figure 2. Showing PA technique and case of burst fracture T12 treated by mesh cage and posterior fixation.

the body to protect the segmental vessels from the excepted injury, subtotal copectomy was performed using burr or by nucletome removing the middle column of the vertebral body from the lateral surface of the body leaving a part of the anterior column. At L1, the origin of diaphragm might be a problem but a piece of body of L1 attached to the origin of the diaphragm was reflected to allow adequate subtotal corpectomy. The disc above and below was opened and curetted and removed by multiple dilator and the curetted disc was filled by cortico-cancaellous strut bone graft alone taken from iliac bone or bone graft with single titanium mesh cage. The diameter and length of mesh cage used was $14 \mathrm{~mm} \times 5 \mathrm{~cm}, 16 \mathrm{~mm} \times 5 \mathrm{~cm}$ and $18 \mathrm{~mm} \times 5.6 \mathrm{~cm}$. After insertion of titanium mesh cage, the pedicular screws were compressed axially to compress the mesh cage in the vertebrae above and below.

In group (IV) TPA technique as shown in Figure 3: the decompression of the neural elements was approached by removing lamina of single or both side with complete facetectomy to allow the bony fracture fragment causing mechanical compression to be easily removed by using specially designed curettes and allow neuroforminal decompression without fear of dural tear or excessive manipulation on the neural element. Through unipedicular or bipedicular approach the corpectomy was done by removal of anterior vertebral column by piecemeal technique without disturbing the anterior longitudinal ligament to prevent anterior dislodgement of cage into abdominal cavity as reported in anterior surgery. Subtotal corpectomy was being done. After decompression of the canal, the disc above and below was opened and curetted and removed by multiple dilator and the curetted disc was filled by bone graft alone or bone graft with central single titanium non expandable mesh cage filled with bone graft. If the thumb surgeon's with two gloves was inserted easily, the mesh cage could be applied smoothly without fear on the neural element. Non expandable titanium mesh cage was inserted into the vertebral body from downwards at the upper end plate of the vertebra below towards upwards the lower end plate of the vertebra above. After that axial compression was done by compressing the pedicular screws in the vertebrae above and below. The diameter and length of mesh cage used was $16 \mathrm{~mm} \times 5 \mathrm{~cm}$ and $18 \mathrm{~mm} \times 5 \mathrm{~cm}$. The decompression was checked and confirmed. The Titanium rods were measured; cut, placed and compression applied.

In all groups, Additional bone graft taken either from posterior superior iliac spine posteriorly, iliac crest anteriorly or resected rib, vertebral body or lamina was putted on the decorticated posteralateral surface and transverse process of the operated level. Suction drainage was applied and the wound was closed in layers. Intraoperative problems, operative time and intraoperative blood loss were recorded.

\subsection{Post-Operative Follows Up}

Intravenous antibiotic was taken for 2 days followed by oral antibiotics for 10 days. Postoperative pain controlled by simple analgesia. X-ray was done (A/P and lateral view) immediately postoperative. The suction drainage was removed after 24 to 72 hours. The cases came again after two weeks for removal of the stitches. After removal of the stitches, the patients started condensed physiotherapy program and strengthening exercises to enhance in neurological deficits improvement. Patients were followed up at $1 \mathrm{~m}, 3 \mathrm{~m}, 6 \mathrm{~m}$ and every 6 month intervals to evaluate the results clinically and radiologically. The patients were followed up till they achieve complete fracture healing, anterior fusion and almost neurological recovery. The surgical correction of kyphosis 


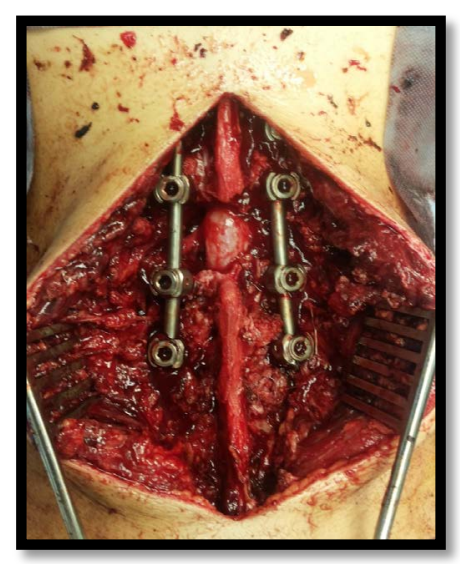

(a)

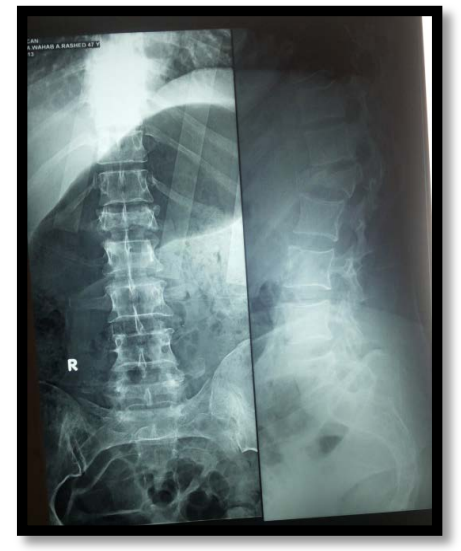

(b)

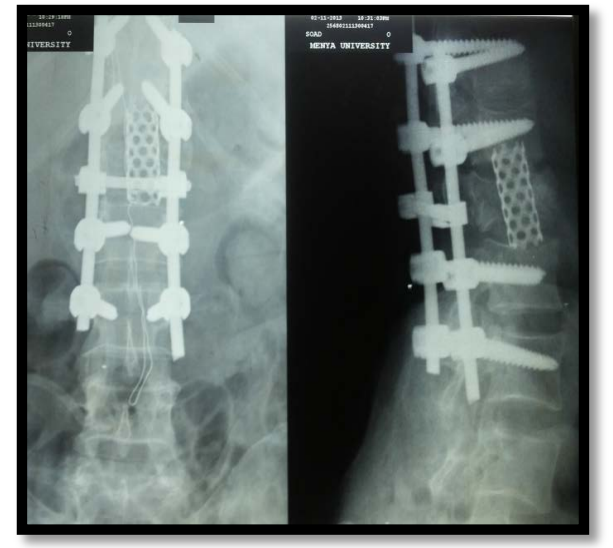

(c)

Figure 3. Showing TPA technique and case of burst fracture of L1 treated by mesh cage and posterior fixation.

was assessed pre and postoperatively. The postoperative loss of correction was assessed by calculating the mean difference between the postoperative values and the values at final follow-up. The following validated outcome scores were additionally assessed at final follow-up: the VAS, the Oswestry Disability Index (ODI), and Denis pain and work scale.

\subsection{Statistical Analysis}

Statistical analysis was carried out by SPSS package, software version 20 and stategraphics (statistical graphics system, statistical graphics corporation, USA). Statistical analysis include One way ANOVA test, Post Hoc test, Mann Whitney test, Person correlation coefficient, Chi square test for categorical data, Paired sample T test, independent $\mathrm{T}$ test, Wilcoxon signed ranks, Kruskal Wallis test, $\mathrm{p}$ value $\{<0.05$ significant, $\mathrm{p}$ value $<0.01$ was considered highly significant $\mathrm{p}$ value $>0.05$ insignificant $\}$.

\section{Results}

Follow up was ranged from 6 to 36 months with its mean $28.98 \pm 4.82$ months with insignificant difference among 4 groups. The longer follow up was for the cases presented late with complicated neurological deficits and cases treated by PA surgery. Fall from height (FFH) was the most common cause of injury among the 4 groups (50\%). L1 was the most common site of fractured involved among 4 groups (42\%). Calacaneal, tibial, talar and distal radial fractures (38\%) were reported in all cases occurred due to FFH (76\%). Calacaneal fracture was the most common associated injuries (22\%). While rib fractures (16\%) were reported in cases occurred due to motor cycle accident. Neurological outcomes according to ASIA motor index: There was significance difference between pre and postoperative in each group $\left(\mathrm{p}<0.001^{*}\right)$ with insignificant difference in the postoperative among 4 groups.

Classification systems: As regard Denis classification, 28 cases were class A among 4 groups with significance difference $\left(0.006^{*}\right)$. As regard to MacAfee's classification burst unstable fractures were the commonest one among 4 groups (40\%) As regard AO classification C class was the most common one (42\%). Load sharing score was ranged from 7 to 9 (mean: $7.94 \pm 0.78$ ) with insignificant difference. TLISS was ranged from 6 to 9 (mean: $7.88 \pm 1.05$ ) with insignificant difference among 4 groups. White Panjabi method was ranged from 6 to 12 (mean: $9.34 \pm 1.42$ ) with significance difference among 4 groups as. There was significant positive correlation between TLISS and load sharing classification $\left(r=0.767\right.$ and $\left.p<0.001^{*}\right)$; significant positive correlation between White and Panjabi method and TLISS ( $\left.\mathrm{r}=0.709, \mathrm{p}<0.001^{*}\right)$ and significant positive correlation between White and Panjabi method and load sharing classification( $\mathrm{r}=0.627, \mathrm{p}<0.001^{*}$ ).

Radiological outcomes: Vertebral body height was corrected from $8 \mathrm{~mm}$ to $13 \mathrm{~mm}$ in the preoperative measures to 18 to $22 \mathrm{~mm}$ (mean: $15 \mathrm{~mm}$ ) postoperatively. The sagittal index of the fractured vertebra was corrected from $12^{\circ}$ to $36^{\circ}$ (mean: $26^{\circ}$ ) in the preoperative period, to $-8^{\circ}$ to $7^{\circ}$ (mean: $3^{\circ}$ ) in the immediate postoperative period and at the final evaluation after two year it was $-9^{\circ}$ to $8^{\circ}$ (mean: $2^{\circ}$ ) with significance difference between 
preoperative and immediate postoperative values and between preoperative and final postoperative values $\left(<0.001^{*}\right)$ in each group.

Vertebral height loss (VHL) ratio was improved from 0.5 to 0.8 (mean: $0.66 \pm 0.09$ ) in the preoperative period to 0.7 to 1 (mean $0.93 \pm 0.07$ ) in the postoperative period with significance difference between the pre and postoperative values in each group $\left(0.001^{*}\right)$ with insignificant difference among 4 groups pre and postoperatively.

According to angle of kyphosis, the mean kyphosis was corrected from $25.50^{\circ} \pm 4.31^{\circ}$ in the preoperative period to $15^{\circ}$ to $33^{\circ}$. Immediately after surgery, the correction of kyphosis was ranged from $-9^{\circ}$ to $7^{\circ}$ with mean $2.08^{\circ} \pm 4.03^{\circ}$. the last final follow up kyphotic angle was ranged from $-9^{\circ}$ to $8^{\circ}$ with its mean $1.43^{\circ} \pm 3.74^{\circ}$ with significance difference between the pre and postoperative kyphotic angle in each group and between the pre and last kyphotic angle in each group $\left(<0.001^{*}\right)$ and insignificant difference among 4 groups in the postoperative and last kyphotic angle.

Spinal canal compromise was corrected from $60 \%$ to $80 \%$ in the preoperative state (mean: $73.36 \% \pm 6.74 \%$ ) to $5 \%$ to $18 \%$ (mean: $12.5 \% \pm 7.5 \%$ ) with significant difference on comparing preoperative and postoperative spinal canal compromise in each group and significant difference among 4 groups in the postoperative state.

The radiological results revealed that there was significant difference among 4 groups as regard initial monosegmental angle, initial spinal canal narrowing, monosegmental surgical correction, postoperative spinal canal narrowing, surgical correction.

\subsection{Time to Surgery}

Time until surgery was ranged from 6 hours to 7 days (mean: $41.28 \pm 49.53 \mathrm{hrs)}$ ). In group (I), the mean time was 3.04 days. In group (II), the mean time was 1.7 days. In group (III), the mean time was 5.8 days. In group (IV), the mean time was 2.6 days with significant difference between four groups $<0.001^{*}$. The cases treated early within 72 hrs improved better than those treated late.

\subsection{Perioperative Outcomes}

Operative time was ranged from 110 to 190 min (mean: $140 \pm 28.14 \mathrm{~min}$ ). The longest operative time reported in group (III) (mean: $179.85 \pm 6.35 \mathrm{~min}$ ) while the shortest operative time reported in group (I) (mean: $116.46 \pm$ $5.42 \mathrm{~min}$ ) with significance difference between 4 groups $\left(\mathrm{p}<0.001^{*}\right)$.

Estimated blood loss (EBL) was ranged from 400 to $850 \mathrm{cc}$ (mean: $535.50 \pm 121.44 \mathrm{cc}$ ). the maximum EBL was reported in group (III) with mean $689.28 \pm 102.15 \mathrm{cc}$, and it was least in group (I) with mean $445 \pm 34.98 \mathrm{cc}$ with significant difference on comparing between the four groups, the $\left(\mathrm{p}<0.001^{*}\right)$.

The hospital stay was ranged from 1 day to 10 days (mean $3.82 \pm 2.26$ days), the hospital stay was less in group (I) with mean $2.06 \pm 0.44$ days and the longer hospital stay was reported in group (III) with mean $6.28 \pm$ 1.3 days with significant difference between the 4 groups $\left(\mathrm{p}<0.001^{*}\right)$.

\subsection{Pulmonary Function Tests}

Vital capacity (VC) was ranged preoperatively and postoperatively 2.19 - 2.4 L (mean: $2.23 \pm 0.03 \mathrm{~L}$ ) and 2.27 $2.88 \mathrm{~L}$ (mean: $2.66 \pm 0.17 \mathrm{~L}$ ) respectively, forced vital capacity (FVC) was ranged preoperatively and postoperatively from $2.12-2.3 \mathrm{~L}$ (mean: $2.16 \pm 0.03 \mathrm{~L}$ ) and from $2.25-2.9 \mathrm{~L}$ mean $(2.58 \pm 0.22 \mathrm{~L})$ respectively, Maximal voluntary ventilation (MVV) was ranged preoperatively and postoperatively from $78.5-80.5 \mathrm{~L}$ (mean $79.62 \pm 0.37 \mathrm{~L}$ ) and from $82.5-90.78 \mathrm{~L}$ (mean $87.79 \pm 3.01 \mathrm{~L}$ ) respectively with significance difference between the pre and postoperative state in each group and significant difference among 4 groups between the pre and postoperative state.

\subsection{Functional Outcome}

Visual analogue score (VAS) was improved from 6 - 9 (mean $7.42 \pm 1.02$ ) preoperatively to 0 - 2 (mean $0.88 \pm$ 0.71 ) postoperatively with significant difference between pre and postoperative VAS in each group $\left(\mathrm{p}<0.001^{*}\right)$ and significant difference in the postoperative state among 4 groups $\left(\mathrm{p}<0.02^{*}\right)$.

Denis pain scale was ranged postoperatively at last final follow up P1 to P3 (mean $1.60 \pm 0.66$ ) while Denis work scale postoperatively at last final follow up was ranged from W1 to W5 (mean $2.30 \pm 1.10$ ). On comparing 
Dennis pain and Denis work in between the 4 groups the p value was insignificant among 4 groups.

Oswestery Disability Index (ODI) was improved preoperatively from $38 \%$ to $78 \%$ (mean $50.5 \% \pm 10.8 \%$ ) to postoperatively from $4 \%$ to $22 \%$ (mean $10.9 \% \pm 4.9 \%$ ), with significant difference between pre and postoperative in each group $\left(\mathrm{p}=0.000^{*}\right)$ and insignificant difference among 4 groups in the pre and postoperative state.

\subsection{Complications}

In group (I), complications were reported in 5 cases (3 cases had deep infection and 2 cases had radiological cage subsidence more than $2 \mathrm{~mm}$ in the lower end plate), In group (II), complications were reported in 14 cases (4 cases had neuroprexia, 4 cases had dural tear and 6 cases had radiological cage subsidence more than $2 \mathrm{~mm}$ in the lower end plate), In group (III), complications were reported in 6 cases (2 cases had superficial infection, 2 cases had radiological cage subsidence more than $2 \mathrm{~mm}$ in the lower end plate and 2 cases had loose screws). In group (IV), one case had superficial infection which treated conservatively. Donor site related complaints were reported in 12 as mild complaints (4 in (I), 3 in (II), 3 in (III) and 2 in (IV)) and in 6 as severe complaints (2 in (I), (II) and (III)) with insignificant difference among 4 groups.

\section{Discussion}

The goals of surgery in thoracolumbar fractures include decompression of the neural elements to facilitate neurological recovery, correction of spinal deformity and fusion with rigid stabilization to prevent delayed neural injuries, maintenance of anatomic alignment and early mobilization of the patient. However, the specific approach to be used in surgical treatment is controversial [12].

Direct decompression, corpectomy, and reconstruction of middle column can be done through the posterior approach either by TLIF, PLIF and TPA but indirect decompression, corpectomy and reconstructions was done by lateral extracaviatary approach (LEC) [13].

As regard PLIF surgery the present study coincides with Schmid et al. [11] and Jun et al. [14] in the following; improvement of the neurological deficit with significant difference between pre and postoperative state $(\mathrm{p}<$ $0.001^{*}$ ), surgical correction of the kyphotic angle from the preoperative to postoperative measure about $24.65^{\circ}$ and less loss of correction in the present study than the other study $\left(1.43^{\circ}\right)$ adequate decompression of the spinal canal postoperatively (61.94\% $\pm 5.25 \%$ ) with significant difference between pre and postoperative spinal canal compromise, operative time was less in our study than others (120.85 $\pm 6.89 \mathrm{~min})$, short hospital stay (2.92 \pm 1.24 day), EBL was less in the present study than others (457.14 \pm 32.53 cc) and improvement of the VAS and ODI score from pre to the postoperative state with total loss of score (6.21 points) and $46.5 \% \pm 7.9 \%$ respectively with significant difference. But the present study reported more complication than other (4 cases had neuroprexia which treated conservatively and improved after 3 months and 4 dural tear sutured by proline $6 / 0$ and 2 cases had cage subsidence but didn't affect kyphotic angle $\left(<10^{\circ}\right)$. The dural tear and neuroprexia are the most common complications in PLIF technique due to excessive manipulation and retraction over the dura and nerve root. The donor site morbidity was reported in 5 cases (3 mild complain and 2 severe complains).

As regard TLIF surgery the present study coincides with Schmid et al. [11], Wang et al. [15], and Aly [16] in the following; improvement of the neurological deficit with significant difference between pre and postoperative state $\left(\mathrm{p}<0.001^{*}\right)$, surgical correction of the kyphotic angle from the preoperative to postoperative measure about $21.73^{\circ} \pm 4.82^{\circ}$ and less loss of correction in the present study than the other study $\left(0.47^{\circ}\right)$ adequate decompression of the spinal canal postoperatively $(64.7 \% \pm 5.75 \%)$ with significant difference between pre and postoperative spinal canal compromise, operative time was less in our study than others (116.46 $\pm 5.32 \mathrm{~min}$ ), shorter hospital stay ( $2.06 \pm 0.44$ day) EBL was less in the present study than others (445 $\pm 34.46 \mathrm{cc}$ ), improvement of the VAS and ODI score from pre to the postoperative state with total loss of score (6.66 points) and $43 \% \pm$ $6.3 \%$ respectively with significant difference. But the present study reported no neurological complication like PLIF surgery but reported three cases had deep wound infection which treated by radical debridement with antibiotics (vancomycin) and improved after 1 month and 2 cases had cage subsidence but didn't affect kyphotic angle $\left(<10^{\circ}\right)$. The donor site morbidity was reported in 6 cases (4 mild complain and 2 severe complains).

As regard PA surgery the present study coincides with Jain et al. [17] and Aebli et al. [18] in the following; improvement of the neurological deficit with significant difference between pre and postoperative state $(\mathrm{p}<$ $0.001^{*}$ ), surgical correction of the kyphotic angle from the preoperative to postoperative measure about $25.64^{\circ} \pm$ $3.82^{\circ}$ and less loss of correction in the present study than the other study $\left(0.07^{\circ}\right)$ adequate decompression of the 
spinal canal postoperatively(57.35\% \pm 5.01\%) with significant difference between pre and postoperative spinal canal compromise, operative time was less in our study than others (179.85 $\pm 6.35 \mathrm{~min})$,longer hospital stay (6.28 \pm 1.3 day) EBL was less in the present study than others (689.28 $\pm 102.15 \mathrm{cc})$, improvement of the VAS and ODI score from pre to the postoperative state with total loss of score (6.21 points) and $40 \% \pm 6.3 \%$ respectively with significant difference. But the present study reported no neurological complication like PLIF surgery but reported two cases had superficial wound infection which treated conservatively and improved after 2 weeks, 2 cases had loose screws and 2 cases had cage subsidence but didn’t affect kyphotic angle $\left(<10^{\circ}\right)$. The donor site morbidity was reported in 5 cases ( 3 mild complain and 2 severe complains).

As regard TPA surgery, the present study coincide with Lee et al. [19], Suzuk et al. [20], Eicker et al. [21], Islam et al. [22], Hofstetter et al. [23], Cho \& Daniel et al. [24], Sasani \& Ozer [25] and Jaing et al. [26]; improvement of the neurological deficit with significant difference between pre and postoperative state $\left(\mathrm{p}<0.001^{*}\right)$ and also surgical correction of the kyphotic angle from the preoperative to postoperative measure about $25.64^{\circ} \pm$ $3.82^{\circ}$ and less loss of correction in the present study than the other study $\left(0.07^{\circ}\right)$, surgical decompression of the canal compromise about $70.42 \pm 6.74$, operative time was less in our study than others (146.28 $\pm 16.2 \mathrm{~min}$ ), EBL was less in the present study than others $(578.57 \pm 25.67 \mathrm{ml})$, relative longer hospital stay $(4.42 \pm 3.08)$ days improvement of the VAS score from pre to the postoperative state with total loss of score (6.71 points) with significant difference between pre and postoperative state. As regard complications, this study reported only 1 case of infection while other study reported more complication like transient nerve root injry. CSF leakage, instrumentation failure and mesh cage malposition. The donor site morbidity reported in 2 cases with mild complaint.

Zhangh et al. [27] did study on 26 patients underwent either a single stage posterior approach (group one, $\mathrm{n}=$ 12) or traditional combined approach (group two, $n=14$ ) for spinal canal decompression and reconstruction this is compared to TPA and PA technique in this study. The results of this study coincide with the results of Zhangh's study as regard the mean follow-up, pre and postoperative kyphotic angle and VHL with no significant difference between both groups ( $p>0.005$ ). The results of this study coincide with Zhangh et al. [27] as regard mean operation time which showed significant difference between both groups $(\mathrm{p}<0.005)$. As regard EBL this study disagree with Zhangh's study as it was less in this study. As regard complications' there was an epidural hematoma in one patient, Loss of correction $\left(5^{\circ}\right)$ was seen in 1 patient due to subsidence of the Titanium mesh cages in group one while In group two, 2 patients had epidural hematoma totally four patients suffered respiratory-related complication, including pneumonia in two, severe atelectasis in one and pleural effusions in one, but complications reported in this study show a significant difference between 2 group; in PA approach included 2 patients had infection, 2 had cage subsidence, 2 had loose screw, no respiratory complications reported as Zhangh's study as this approach done by retroperitoneal, retropleural, extra diaphragmatic not direct anterior as Zhangh's study and 1 case had superfacial infection in TPA group which was resolved by medical treatment after 1 month.

No similar study was done to compare between the four techniques. On comparing between 4 groups, there was no significant difference in the postoperative neurological improvement, post and last kyphotic angle, post VHL ratio and functional outcomes (VAS, ODI, Denis pain \& work scale) which prove that the different surgical techniques either posterior or anterior can correct the kyphotic angle and VHL and improve the neurological deficit and functional outcomes.

There was significant difference in the postoperative spinal canal compromise which shows relative increase in group (III) (PA) than other groups. There were also significant differences in between the 4 groups as regard operative time, EBL and hospital stay as the results revealed that these parameters are more increased in group (III) (PA) and less in the other 3 groups. As regard the pulmonary function test, there was significant difference in between the 4 groups as it was relatively affected in group (III) (PA) than the other 3 groups. There was significant difference as regard complications as every group had its reported complications but the complications were relatively less in group (IV) (TPA) and group (I) (TLIF) and more complications were reported in group (II) so that simultaneous anterior reconstructions with decompression and posterior instrumentation can be achieved from posterior approach either by TLIF, PLIF and TPA. Lateral extracaviatary approach can achieve threecolumn stabilization without laminectomy to preserve the posterior tension surface of the vertebra and without disturbing the chest cavity and diaphragm but this approach is technique demanding and time consuming than other techniques. Overall, mastering four techniques will allow the spine surgeon to be more flexible in specific situations. 


\section{Conclusion}

Three-column stabilization in thoracolumbar spine fractures could be obtained by one stage anterior reconstruction and posterior stabilization by different techniques as demonstrated in this study and all these techniques showed satisfactory results as regards full decompression of the vertebral canal from posterior approach only, improvement in the neurological function and kyphotic angle, less complications rate and more safe than staged combined anterior and posterior operations and decrease late pain and deformity. As regards TLIF \& PLIF techniques, it can be concluded that both techniques less in blood loss, operative time, and hospital stay, but complications are more reported with PLIF surgery. As regards PA surgery, it can be concluded that this technique has more blood loss, longer operative time, more hospital stay and may affect pulmonary function. Also it can be concluded that TPA has more benefits as it is—-safer, less in complications, less in operative time, blood loss, early rehabilitation and less in hospital stay.

\section{References}

[1] Lukas, R., Suchomel, P. and Sram, J. (2006) Surgical Treatment of Thoracolumbar Spine Fractures. Coluna/Columna, 5, 84-89.

[2] Browner, B.D., Jupiter, J.B., Levine, A.M., et al. (2008) Thoracic and Upper Lumbar Spine Injuries in Skeletal Trauma. In: Lee, Y., et al., Eds., Chapter 30, 4th Edition, WB Saunders Company, 500-520.

[3] Denis, F. and Burkus, J.K. (1993) Classification and Treatment of Posttraumatic Kyphosis in the Thoracic and Lumbar Spine. Seminars in Spine Surgery, 5, 187-198.

[4] Schnee, C.L. and Ansell, L.V. (1997) Selection Criteria and Outcome of Operative Approaches for Thoracolumbar Burst Fractures with and without Neurological Deficit. Journal of Neurosurgery, 86, 48-55. http://dx.doi.org/10.3171/jns.1997.86.1.0048

[5] Taylor, R.S., Fritzell, P. and Taylor, R.J. (2007) Balloon Kyphoplasty in the Management of Vertebral Compression Fractures: An Updated Systematic Review and Meta-Analysis. European Spine Journal, 16, 1085-1100. http://dx.doi.org/10.1007/s00586-007-0308-z

[6] Jain, A.K., Dhammi, I.K., Prashad, B., et al. (2008) Simultaneous Anterior Decompression and Posterior Instrumentation of the Tuberculous Spine Using an Anterolateral Extrapleural Approach. Journal of Bone and Joint Surgery, 90, 1477-1481. http://dx.doi.org/10.1302/0301-620X.90B11.20972

[7] Raja, R.A. (2010) Management of Thoracolumbar Spine Injuries at Tertiary Care Hospital. Journal of Ayub Medical College Abbottabad, 22, 171-175.

[8] Kaneda, K., Taneichi, H., Abumi, K., et al. (1997) Anterior Decompression and Stabilization with the Kaneda Device for Thoracolumbar Burst Fractures Associated with Neurological Deficits. Journal of Bone and Joint Surgery [American Volume], 79, 69-83.

[9] Payer, M. (2006) Unstable Burst Fractures of Thoracolumbar Juncation: Treatment by Posterior Bisegmental Correction/Fixation and Staged Anterior Corpectomy and Titanium Cage Implantation. Acta Neurochirurgica (Wien), 148, 299-306. http://dx.doi.org/10.1007/s00701-005-0681-5

[10] Lange, U., Edeling, S., Knop, C., et al. (2006) Titanium Vertebral Body Replacement of Adjustable Size. A Prospective Clinical Trial. Unfallchirurg, 109, 733-742. http://dx.doi.org/10.1007/s00113-006-1090-9

[11] Schmid, R., Krappinger, D., Blauth, M. and Kathrein, A. (2011) Mid-Term Results of PLIF/TLIF in Trauma. European Spine Journal, 20, 395-402. http://dx.doi.org/10.1007/s00586-010-1615-3

[12] Schnee, C.L. and Ansell, L.V. (1997) Selection Criteria and Outcome of Operative Approaches for Thoracolumbar Burst Fractures with and without Neurological Deficit. Journal of Neurosurgery, 86, 48-55. http://dx.doi.org/10.3171/jns.1997.86.1.0048

[13] Lin, B., Chen, Z., Guo, Z., Liu, H. and Yi, Z.K. (2011) Anterior Approach versus Posterior Approach with Subtotal Corpectomy, Decompression, and Reconstruction of Spine in the Treatment of Thoracolumbar Burst Fractures: A Prospective Randomized Controlled Study. Journal of Spinal Disorders \& Techniques. www.jspinaldisorders.com

[14] Jun, D.S., Yu, C.H. and Ahn, B.G. (2011) Posterior Direct Decompression and Fusion of Lower Thoracic and Lumbar with Neurological Deficit. Asian Spine Journal, 5, 146-154. http://dx.doi.org/10.4184/asj.2011.5.3.146

[15] Wang, L., Li, J., Wang, H., Yang, Q., Lv, D., Zhang, W.G., et al. (2014) Posterior Short Segment Pedicle Screw Fixation and TLIF for the Treatment of Unstable Thoracolumbar/Lumbar Fracture. BMC Musculoskeletal Disorders, 15, 40. http://dx.doi.org/10.1186/1471-2474-15-40

[16] Aly, T.A. (2011) Spinal Shortening and Monosegmental Posterior Spondylodesis in the Management of Dorsal and Lumbar Unstable Injuries. Journal of Neurosciences in Rural Practice, 2, 17-22. 
http://dx.doi.org/10.4103/0976-3147.80082

[17] Jain, A.K., Dhammi, I.K., Jain, S. and Kumar, J. (2010) Simultaneously Anterior Decompression and Posterior Instrumentation by Extrapleural Retroperiteoneal Approach in Thoracolumbar Lesions. Indian Journal of Orthopaedics, 44, 409-416. http://dx.doi.org/10.4103/0019-5413.69315

[18] Aebli, N., Kaiser, T., Moulin, P. and Krebs, J. (2014) Short-Segment Posterior Instrumentation Combined with Anterior Spondylodesis Using an Autologous Rib Graft in Thoracolumbar Burst Fractures. Acta Orthopaedica, 85, 84-90. http://dx.doi.org/10.3109/17453674.2013.871137

[19] Lee, Y.M., Cho, Y.W., Kim, J.S., Kim, K.H., Lee, I.C. and Bae, S.D. (2006) Anterior and Posterior Stabilization by One Stage Posterolateral Approach in the Unstable Fracture of Thoracolumbar and Lumbar Spine. Journal of Korean Neurosurgical Society, 40, 22-27.

[20] Suzuki, T., Abe, E., Miyakoshi, N., Murai, H., Kobayashi, T., Abe, T., et al. (2012) Anterior Decompression and Shortening Reconstruction with a Titanium Mesh Cage through a Posterior Approach Alone for the Treatment of Lumbar Burst Fracture. Asian Spine Journal, 6, 123-130. http://dx.doi.org/10.4184/asj.2012.6.2.123

[21] Eicker, S.O., Cornelius, J.F., Steiger, H. and Hänggi, D. (2012) 360-Degree Osteosynthesis via a Posterolateral Transpedicular Approach in High-Risk Patients. European Spine Journal, 21, 1207-1213. http://dx.doi.org/10.1007/s00586-012-2150-1

[22] Islam, A., Sakeb, N. and Mahmood, E. (2012) Evaluation of the Results of Posterior Decompression, Corpectomy and Instrumentation in Traumatic Unstable Thoraco-Lumbar Burst Fractures. BSMMU, 5, 35-41.

[23] Hofstetter, C.P., Chou, D., Newman, B., Aryan, H.E., Girardi, F.P. and Härtl, R. (2011) Posterior Approach for Thoracolumbar Corpectomies with Expandable Cage Placement and Circumferential Arthrodesis: A Multicenter Case Series of 67 Patients. Journal of Neurosurgery: Spine, 14, 388-397. http://dx.doi.org/10.3171/2010.11.SPINE09956

[24] Chou, D. and Daniel, C. (2011) Mini-Open Transpedicular Corpectomies with Expandable Cage Reconstruction. Journal of Neurosurgery: Spine, 14, 71-77. http://dx.doi.org/10.3171/2010.10.SPINE091009

[25] Sasani, M. and Ozer, A.F. (2009) Single-Stage Posterior Corpectomy and Expandable Cage Placement for Treatment of Thoracic or Lumbar Burst Fractures. Spine (Phila Pa 1976), 34, E33-E40.

[26] Jiang, R., Wu, H., Wang, J.C., Li, W.X. and Wang, Y. (2011) Paraspinal Approach for Thoracolumbar Fracture. Chinese Journal of Traumatology, 14, 3-6.

[27] Zhangh, Q., Lu, G., Wang, X. and Li, J. (2014) The Significance of Removing Ruptured Intervertebral Discs for Interbody Fusion in Treating Thoracic or Lumbar Type B and C Spinal Injuries through a One-Stage Posterior Approach. PLOS ONE, 9, e97275. 
Scientific Research Publishing (SCIRP) is one of the largest Open Access journal publishers. It is currently publishing more than 200 open access, online, peer-reviewed journals covering a wide range of academic disciplines. SCIRP serves the worldwide academic communities and contributes to the progress and application of science with its publication.

Other selected journals from SCIRP are listed as below. Submit your manuscript to us via either submit@scirp.org or Online Submission Portal.
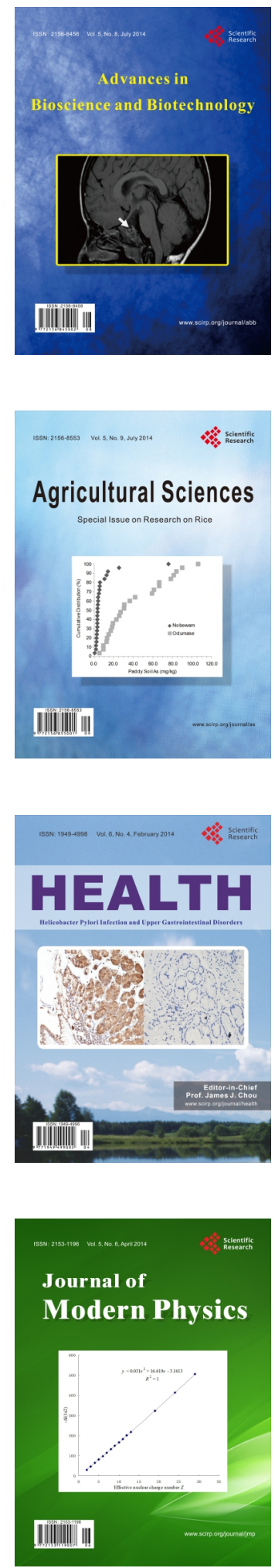
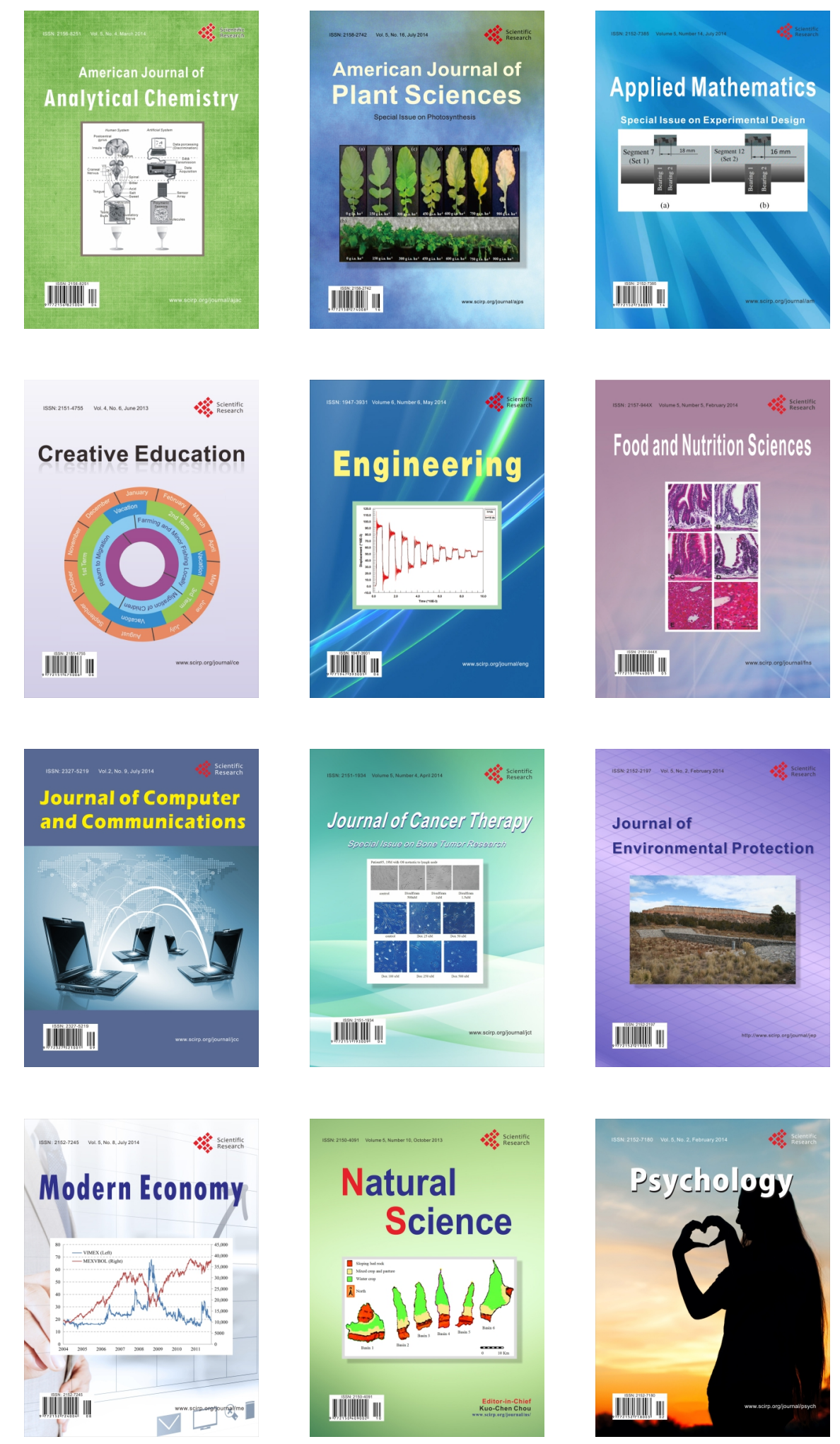